\title{
MODELO DE AVALIAÇÃO FÍSICO-FUNCIONAL DA COLUNA VERTEBRAL
}

\author{
Neusa Maria Costa Alexandre* \\ Marco Antonio Alves de Moraes**
}

Alexandre NMC, Moraes MAA. Modelo de avaliação físico-funcional da coluna vertebral. Rev Latino-am Enfermagem 2001 março; 9(2): 6775.

O presente trabalho descreve os métodos semiológicos que devem ser empregados na exploração postural e na avaliação da coluna vertebral, dentro da assistência à saúde em nível primário. Os métodos empregados nessa propedêutica sistematizada englobam o histórico e um exame físico específico composto de: inspeção estática e exame postural; inspeção dinâmica; palpação; avaliação da força e flexibilidade musculares; exame neurológico e manobras especiais.

UNITERMOS: exame físico, coluna vertebral, dor lombar

\section{SPINAL CORD PHYSICAL ASSESSMENT MODEL}

The study describes semiological methods that must be employed in posture and spinal cord evaluation, considering primary health care. The methods used in this study involve the patient's history, and a specific physical examination which includes a static inspection, posture examination, dynamic inspection, palpation, muscle strength and flexibility assessment, neurological examination and special tests.

KEY WORDS: physical assessment, spinal cord, low back pain

\section{MODELO DE EVALUACIÓN FÍSICO-FUNCIONAL DE LA COLUMNA VERTEBRAL}

El presente trabajo describe un modelo de evaluación fisico-funcional que puede ser empleado en la evaluación postural y en la valoración de la columna vertebral dentro de la atención a la salud en nivel primario. Los métodos empleados en esa propedéutica sistematizada engloban la historia clínica y un examen físico específico compuesto de inspección estática y examen de la postura, inspección dinámica, palpación, evaluación de la fuerza y flexibilidad muscular, examen neurológico y maniobras especiales.

TÉRMINOS CLAVES: examen físico, columna vertebral, dolor de la región lumbar

\section{INTRODUÇÃO}

As afecções do sistema músculo-esquelético, particularmente as algias vertebrais, constituem um problema tão sério na sociedade moderna, que equipes multidisciplinares procuram desenvolver normas para uma adequada avaliação da coluna vertebral $^{(1-3)}$. Especificamente sobre a enfermagem, recorda- se que o Currículo Mínimo de Enfermagem sofreu uma reformulação, com a resolução do Conselho Federal de Educação nº 314/94, em que a disciplina Semiologia e Semiotécnica de Enfermagem, que integra a Área Fundamentos da Enfermagem, passa a fazer parte de um dos conteúdos programáticos obrigatórios. Além disso, considera-se que a enfermagem deve utilizar estratégias de metodologia científica para subsidiar suas ações. Dentro deste

\footnotetext{
* Enfermeira. Professor Assistente Doutor do Departamento de Enfermagem da Faculdade de Ciências Médicas-UNICAMP. Endereço: Dr. Miguel Pierro, 128 - Cidade Universitária - 13083-300 - Campinas - São Paulo - Brasil. E-mail: neusalex@fcm.unicamp.br

** Fisioterapeuta. Centro de Saúde da Comunidade da UNICAMP. Pós-graduando da Faculdade de Educação Física - UNICAMP. Prof. Adjunto do Curso de Fisioterapia da Universidade Paulista-UNIP
} 
contexto, os estudantes de enfermagem precisam ser preparados para realizar uma propedêutica vertebral sistematizada, empregando métodos semiológicos específicos. Como integrantes de um Grupo de Coluna, os autores do presente trabalho promovem um atendimento interdisciplinar individualizado, o que proporciona uma avaliação de vários aspectos das afecções relacionadas com a coluna vertebral, com ênfase nos aspectos ocupacionais e ergonômicos.

Este estudo tem por objetivo descrever as etapas essenciais do histórico e do exame físico de uma avaliação postural e da coluna vertebral, com vistas a fornecer uma abordagem mais racional e consistente dentro de uma assistência à saúde em nível primário.

Os métodos semiológicos descritos nessa abordagem englobam a anamnese e um exame físico específico que emprega os seguintes métodos: inspeção estática e exame postural; inspeção dinâmica; palpação; avaliação da força e flexibilidade musculares; exame neurológico e manobras especiais. Para facilitar o registro dos dados coletados, desenvolveu-se uma ficha específica que é utilizada, rotineiramente, durante a avaliação do Grupo de Coluna (Anexo 1).

\section{HISTÓRICO ESPECÍFICO}

Lembrando que o paciente precisa sempre ser visto como um todo, a primeira etapa dessa abordagem é a entrevista que deve ser realizada em ambiente tranqüilo e sem interrupções, deixando o paciente usar sua linguagem ${ }^{(4)}$.

\section{1 - Identificação e informações gerais}

A anamnese inicia-se pela identificação, contendo elementos tais como idade, sexo, peso e altura. Não se deve esquecer também de investigar questões que envolvem a ocupação atual e as pregressas, visto que muitas das afecções que atingem a coluna vertebral estão relacionadas com as atividades laborativas ${ }^{(5)}$. A avaliação de antecedentes pessoais e familiares e a investigação de patologias concomitantes auxiliam na detecção de doenças específicas, sendo necessário verificar a presença de neoplasia maligna, tuberculose, cirurgia, entre outros. Deve-se, igualmente, avaliar a presença de manifestações sistêmicas que acompanham a sintomatologia vertebral, tais como anorexia, emagrecimento e febre. Sintomas genitourinários e disfunção esfincteriana também devem ser pesquisados, pois podem estar relacionados com compressão neural ${ }^{(6)}$. Questões relacionadas a fatores psicossocias, econômicos e estilo de vida fornecem, da mesma forma, pistas importantes, visto que podem influenciar significantemente o início e a progressão de problemas musculo-esqueléticos ${ }^{(7)}$. Faz-se necessário, então, investigar os aspectos relacionados sobre crenças quanto à afecção; medo de dor e de retornar às atividades normais; presença de ansiedade e depressão bem como de fatores que envolvem o trabalho como suporte social, satisfação, percepções sobre demanda da carga de trabalho e as questões legais trabalhistas ${ }^{(7-8)}$. A utilização de álcool e de tabagismo também deve ser determinada. Já existem evidências da associação entre o tabagismo e dores nas costas em adultos $^{(9)}$, sendo que o uso de álcool e fumo estão relacionados com o aumento do risco de osteoporose ${ }^{(10)}$.

Nessa parte da entrevista, procura-se levantar dados que fornecerão subsídios para a formulação de orientações ergonômicas e posturais específicas para cada paciente. Dentro desse contexto, investiga-se as posturas adotadas, as atividades, os equipamentos e mobiliários e 0 ambiente de trabalho. Indaga-se sobre a prática de algum tipo de atividade física regular, tipo de colchão e travesseiros utilizados e a posição ao dormir, apresentando também os principais pontos que não podem ser esquecidos ao se tentar detectar condições realmente graves na coluna vertebral, denominadas "red flags" (11). Para pesquisar câncer e infecção, esses autores destacam: idade acima de 50 e abaixo de 20; história de câncer; febre e perda de peso; infecção bacteriana recente; imunossupressão; uso de drogas e dor que piora durante a noite e na posição supina. Para detectar possíveis fraturas ${ }^{(11)}$, recomendam pesquisar traumas e, para comprometimento neurológico severo, destacam incontinência urinária ou fecal e déficit neurológico progressivo em membros inferiores.

\section{2 - Sinais e sintomas específicos}

Após coletar os dados da identificação, é importante permitir que o paciente coloque livremente o motivo que o levou a procurar auxílio. A grande maioria dos pacientes procura auxílio, tendo como queixa principal a dor, que deve ser analisada nos seguintes aspectos:

- Localização: A dor pode estar localizada em um segmento da coluna (cervical, dorsal e lombar) ou em toda a sua extensão. Tendo como referência sua localização, pode-se reconhecer as síndromes: cervicalgia, dorsalgia e lombalgia.

- Intensidade: Pode ser classificada em leve, moderada e intensa. Os processos degenerativos geralmente causam dor de pequena e média intensidade, enquanto que nas afecções compressivas ela costuma ser intensa ${ }^{(12)}$.

Considera-se importante controlar alguns dados que servirão para avaliar sua evolução. Como sugestão, o paciente poderá responder um questionário em cada visita. A intensidade da dor pode ser avaliada por uma escala numérica que varia de 0 a 100, 
sendo que 0 significa 'sem dor' e 100 'a pior dor imaginável, ${ }^{(13)}$. Para a localização das áreas de dor é possível utilizar uma figura humana $^{(14)}$.

- Duração: Deve-se investigar quando a dor iniciou e se ela é contínua ou intermitente. Foi definida dor aguda aquela que dura 7 dias ${ }^{(8)}$; subaguda quando a duração vai de 1 a 4 semanas; 'em risco' quando dura de 4 a 12 semanas e crônica com mais de 12 semanas.

- Modo de início: Súbito ou gradual.

- Ritmo: Deve-se pesquisar a associação da dor com o repouso e com os movimentos. Uma dor contínua, mesmo em repouso, que se agrava com os movimentos ocorre na hérnia discal ${ }^{(12)}$. De uma forma geral, as doenças inflamatórias pioram após repouso prolongado e as mecânicas ou degenerativas melhoram com o repouso e pioram com o uso da articulação, geralmente à tarde ${ }^{(4,15)}$.

- Irradiação: A dor da região lombar pode irradiar-se para os membros inferiores e da região cervical para os membros superiores. Essa irradiação sugere a possibilidade de comprometimento radicular, cuja etiologia pode ser degenerativa (discoartrose) ou compressiva (hérnia discal) ${ }^{(12)}$. Quando a dor irradia abaixo do joelho sugere uma verdadeira radiculopatia do que quando ela irradia somente para a coxa posterior ${ }^{(1)}$.

- Fatores precipitantes e agravantes: Deve-se procurar verificar o relacionamento da dor com algum tipo de esforço físico, postura, movimento, esportes, tensão emocional e trauma.

- Fatores de melhora: Repouso, variações do decúbito, calor local, etc.

Não se deve esquecer de pesquisar sinais e sintomas concomitantes tais como parestesias (formigamento, dormência), fraqueza muscular, rigidez pós-repouso e exacerbação da dor por ocasião de tosse e espirro ${ }^{(4,15)}$. Ao discorrer sobre avaliação da região cervical autores ${ }^{(16)}$ relatam que dores nesta região, por compressão neural, são agravadas durante tosse, espirro e defecação por aumentarem a pressão intracranial. Uma história persistente de parestesia e debilidade na perna aumenta a probabilidade de um envolvimento neurológico ${ }^{(1)}$. Outras questões importantes que devem fazer parte da entrevista inicial inclui respostas a outros tratamentos e história de traumas significantes tais com queda de altura e acidente de carro ${ }^{(11)}$.

\section{EXAME FÍSICO ESPECÍFICO}

A propedêutica física da coluna vertebral deve ser iniciada em um sentido global, isto é correlacionando cabeça, coluna, bacia e membros inferiores, para depois passar à exploração segmentar. A justificativa para isto é que a interdependência funcional com esses elementos altera a estática e a dinâmica da coluna vertebral ${ }^{(17)} .0$ exame físico específico procura coletar, de uma forma sistemática, dados relacionados com a detecção de determinados defeitos posturais e alterações musculoligamentares. Os pacientes do sexo masculino devem estar com um calção de banho e as do sexo feminino com um avental aberto na região dorsal.

Compreende a inspeção estática e dinâmica e a palpação.

\section{1 - Inspeção estática e exame postural}

Os defeitos posturais podem ser congênitos ou adquiridos (doença, hábito, fraqueza muscular, etc.) sendo que sua importância reside na anomalia postural que representa ${ }^{(18-20)}$. Na postura deficiente existe uma relação anormal entre as diversas partes do corpo, resultando em solicitação excessiva dos elementos de apoio e na diminuição do perfeito equilíbrio do corpo sobre a base de sustentaçãa $^{(21)}$. Dessa forma, os defeitos posturais determinam traumas crônicos sobre as articulações e estruturas associadas, sendo, então, considerados elementos favorecedores ou agravantes da patogenia das algias da coluna vertebral ${ }^{(19)}$. Estes fatos justificam a importância de se realizar um exame postural cuidadoso e minucioso. A inspeção deve ser realizada em um local com boa iluminação onde o paciente possa caminhar, procurando inicialmente observar a postura, a marcha, atitudes antálgicas, abdômen flácido, entre outros ${ }^{(12,22)}$.

Nessa fase do exame, pode-se utilizar um simetógrafo, ou seja, um retículo que ocupa toda a altura de um indivíduo com um tablado fixo. Um braço de madeira está fixado, perpendicularmente, à moldura superior, projetando-se aproximadamente $60 \mathrm{~cm}$ adiante. Um fio de prumo, preso a este braço, divide em duas metades iguais o retículo em sentido vertical ${ }^{(21,23)}$. Os pacientes devem ser examinados descalços e sob diferentes ângulos: de frente, de lado e de costas. Dessa forma, procura-se detectar as seguintes alterações:

\subsection{1 - Alterações do alinhamento e das curvaturas da coluna vertebral}

\section{- Coluna cervical}

No segmento cervical procura-se detectar um aumento da lordose ou sua retificação e protusão de C7. Pode-se também observar alterações na posição da cabeça, como inclinações laterais e projeção para frente ${ }^{(4,23)}$.

\section{- Coluna dorsal}

Na região torácica nota-se um aumento ou retificação da cifose e a presença de escoliose.

\section{- Coluna lombar}

Em relação à região lombar, verifica-se a presença de 
hiperlordose, retificação da lordose e escoliose. A coluna vertebral, considerada no seu conjunto, é retilínea, quando observada de frente ou posteriormente. Ao contrário, quando é vista em sentido lateral, apresenta quatro curvaturas normais que são, de cima para baixo: lordose cervical, com concavidade posterior; cifose dorsal, com convexidade posterior; lordose lombar, com concavidade posterior e curvatura sacral, que é fixa, em virtude da soldadura definitiva das vertebras sacrais ${ }^{(20,24)}$. As alterações das curvaturas podem ser produzidas por traumas, defeitos congênitos, posturas inadequadas, entre outros. A escoliose é o desvio lateral da coluna vertebral. Pode aparecer nas seguintes localizações: lombar, torácica, toracolombar e dupla curva ${ }^{(25)}$. São classificadas em estruturadas e não estruturadas. A escoliose estruturada é identificada, clinicamente, quando o paciente faz a flexão do tronco, notando-se então o aparecimento de uma gibosidade, que está sempre na convexidade da curva. Radiologicamente, os corpos vertebrais rodam para o lado da convexidade e os processos espinhosos para a concavidade da curva ${ }^{(12)}$. Como as alterações da escoliose podem originar problemas graves, seu diagnóstico precoce é muito importante ${ }^{(21)}$.

\subsection{2 - Alterações da cintura escapular}

Verifica-se o nível dos ombros e das escápulas e a presença de alterações do posicionamento das escápulas (ex. aladas, planas).

\subsection{3 - Alterações da cintura pélvica}

Observa-se se uma inclinação e a presença de retroversão ou anteroversão. 0 desnivel dos quadris tanto pode ser em razão da desigualdade de comprimento dos membros inferiores, quanto à presença de curvatura anormal da coluna lombar ${ }^{(21)}$.

\subsection{4 - Alterações em membros inferiores}

Procura-se notar joelhos valgos, varos, recurvados e também tíbias varas. As duas deformidades mais comuns do joelho são: excesso de angulação valgo (joelhos em X) ou varo (joelhos arqueados) ${ }^{(26)}$. A avaliação dos pés merece atenção especial pois recebem todo o peso corporal. Ao se examinar a altura do arco longitudinal pode-se constatar sua diminuição (pé plano) ou aumento (pé cavo) Em relação aos dedos, uma das anomalias adquiridas é 0 hálux valgo que é o desvio externo do hálux ${ }^{(4)}$. É importante examinar os calcanhares sendo que, normalmente, o tendão de Aquiles e o bordo posterior do pé estão situados na mesma linha vertical. Podese notar um desvio do calcanhar para fora (varo)ou para dentro (valgo) ${ }^{(4)}$. Quando houver suspeita de que os membros inferiores tenham comprimentos diferentes, deve-se realizar uma avaliação.
Coloca-se o paciente em decúbito dorsal e alinha-se os membros inferiores, simetricamente, em extensão. Com uma fita métrica, verifica-se a distância compreendida entre as espinhas ilíacas ânterosuperiores e os maléolos internos ou da cicatriz umbilical até os maléolos internos ${ }^{(26)}$.

\section{2 - Inspeção dinâmica}

Nesta fase do exame, procura-se avaliar a amplitude dos movimentos da coluna e pesquisar a presença de dor à movimentação de cada segmento, o que permite verificar suas limitações funcionais. 0 paciente continua na posição de pé e realiza os movimentos, separadamente, por região da coluna.

\subsection{1- Coluna cervical}

Os movimentos efetuados pela coluna vertebral são: flexão, extensão, rotação e inclinação ${ }^{(12,26-27)}$.

- Flexão: Pedir ao paciente para mover anteriormente a cabeça, o alcance normal permitirá que encoste o queixo na face anterior do tórax.

- Extensão: A cabeça é projetada para trás, o alcance é normal, quando o paciente consegue olhar diretamente para o teto.

- Rotação direita e esquerda: A rotação normal permite que o queixo do paciente quase se alinhe ao ombro.

- Inclinação direita e esquerda: Normalmente, o paciente será capaz de inclinar a cabeça cerca de $45^{\circ}$ em direção ao ombro.

\subsection{2- Coluna torácica e lombossacra}

- Flexão: Solicitar ao paciente que tente encostar as mãos no chão, mantendo os joelhos retos. 0 normal é o paciente quase alcançar os dedos dos pés ${ }^{(6)}$.

- Extensão: Quando o tronco é projetado para trás $\left(30^{\circ}\right)$.

- Rotação direita e esquerda

- Inclinação direita e esquerda. 0 paciente deve inclinar-se até alcançar a cabeça da fíbula ${ }^{(6)}$.

De uma forma geral, a dor aumentada durante a flexão sugere anormalidades discais e, durante a extensão, sugere alterações degenerativas nos elementos posteriores da coluna vertebral ou estenose $^{(6)}$.

\section{3 - Palpação}

\subsection{1 - Dor à palpação de processos espinhosos}

Seguindo as recomendações ${ }^{(17)}$, essa fase do exame deve 
ser realizada pela compressão da coluna vertebral com a polpa do polegar direito e o resto da mão espalmada sem apoiar no tegumento do paciente. Avalia-se a sensibilidade dolorosa da região cervical com o paciente sentado, orientado para relaxar a musculatura do pescoço e da cintura escapular, colocando-se o examinador por detrás do paciente. A palpação de toda a coluna pode também ser realizada com o paciente deitado em decúbito ventral.

\subsection{2 - Alterações do tônus muscular}

A consistência da massa muscular deve ser avaliada através da compressão digital ${ }^{(17,25)}$. Sistematicamente devem ser palpadas a musculatura paravertebral, buscando-se contraturas e zonas dolorosas.

\section{4 - Avaliação da força e flexibilidade musculares}

Os testes de avaliação muscular têm por objetivo detectar um desequilibrio muscular produzido por debilidade muscular ou por falta de flexibilidade, ou ambas, e devem ser verificados, precocemente, para prevenir deformidades permanentes. Essas análises das ações musculares são essenciais para auxiliar na elucidação diagnóstica e também para ser possível a prescrição de exercícios terapêuticos. 0 termo força é usado para significar a habilidade de um músculo produzir ou resistir a uma força. Para determinar essa força, mede-se a quantidade de resistência que 0 sistema de uma alavanca muscular pode vencer ou manter ${ }^{(28-29)}$. A flexibilidade tem sido definida como mobilização, liberdade para mover ou, tecnicamente, uma qualidade física expressa pela amplitude de movimento. Pode ser avaliada em um grupo de articulações ou, isoladamente, pela sua especificidade ${ }^{(30-31)}$. A finalidade dos testes de flexibilidade é determinar se o grau de movimentação articular, permitido pelo comprimento do músculo, está normal ou limitado.

\section{5 - Exame neurológico}

0 exame neurológico deve ser realizado em pacientes com dor irradiada para os membros superiores ou inferiores, uma vez que as repercussões clínicas nesses membros podem levar a alterações dos reflexos, da sensibilidade e da força muscular. Em relação à região lombar ${ }^{(1)}$, é sugerido um exame neurológico simplificado, justificando que $90 \%$ das radiculopatias, clinicamente significantes, devidas à hérnia de disco intervertebral, envolvem as raízes L5 (espaço L4-L5) ou S1 (espaço L5-S1). Pode ser iniciado, pedindo-se ao paciente que deambule normalmente para avaliação do tipo de marcha. Em seguida, ele deve caminhar na ponta dos pés e nos calcanhares para testar as raízes $\mathrm{S} 1$ e $\mathrm{L} 5$, respectivamente $^{(6,25)}$.

A patologia mais comum da coluna cervical é a doença degenerativa discal que pode causar sintomas de compressão radicular , atingindo as raízes do plexo cervical (C1-C4), ocasionando dor que se irradia para a região occipital e ombros e as raízes do plexo braquial $\left(\mathrm{C}^{2}-\mathrm{T} 1\right)^{(15)}$. 0 exame neurológico baseia-se no fato de que as patologias da coluna cervical freqüentemente ocasionam sintomas ao membro superior, via plexo braquial ${ }^{(26)}$.

\subsection{1 - Reflexos}

Os reflexos podem ser classificados como normais, aumentados, diminuídos e abolidos ${ }^{(26)}$. Os reflexos podem estar diminuídos ou abolidos nos casos de compressão radicular, como ocorre na hérnia distal e na presença de osteófito posterior ${ }^{(18,32)}$. Em relação às afecções da região lombar, é necessário pesquisar os reflexos profundos patelar e aquileu. Ao percutir o tendão, solicitase ao paciente para entrelaçar os dedos e tentar separá-los.

- Reflexo Patelar: É um reflexo mediado por nervos oriundos da raiz de L2, L3 e L4, mas predominante de L4. Clinicamente é considerado como um reflexo de L4. 0 paciente deve estar sentado com as pernas pendentes, percute-se o tendão patelar com um golpe curto e rápido, logo abaixo da patela e observa-se a extensão do joelho. 0 procedimento deve ser repetido na perna oposta.

- Reflexo Aquileu: É um reflexo suprido pelos nervos oriundos do nível neurológico de S1. Para testá-lo, tensione levemente o tendão de Aquiles, por meio de uma discreta dorsiflexão do pé. Percute-se o tendão e observa-se uma flexão plantar súbita e involuntária.

Nas cervicobraquialgias pesquisam-se os reflexos dos membros superiores bicipital, tricipital e braquiorradial.

- Reflexo Bicipital: Avalia primariamente a integridade do nível neurológico de C5. Com o braço do paciente parcialmente fletido, coloca-se o polegar no tendão do bíceps que se aloja na fossa cubital. Golpeia-se diretamente o seu polegar. Observa-se a flexão do cotovelo.

- Reflexo Tricipital: É uma função do nível neurológico de C7. Flexionase o braço do paciente e percute-se o tendão do tríceps acima do cotovelo. Observa-se a extensão do cotovelo.

- Reflexo Braquiorradial: Seu reflexo é função de C6. 0 paciente deve manter a mão apoiada. Percute-se de 2,5 a $5 \mathrm{~cm}$ acima do punho.

\subsection{2 - Sensibilidade}

A sensibilidade superficial pode ser dividida em tátil, térmica e dolorosa ${ }^{(12)}$. A sensibilidade dolorosa é avaliada com um estilete rombo. No caso da avaliação da sensibilidade tátil, pode-se usar um 
pincel pequeno ou um chumaço de algodão, que devem ser roçados de leve em várias partes do corpo. 0 paciente deve manter os olhos fechados durante o procedimento e assim compara-se as regiões simétricas, nos dois lados do corpo. Alguns autores ${ }^{(1)}$ recomendam que, na avaliação de lombalgias em centros de atenção em nível primário, é suficiente pesquisar a sensibilidade tátil fina nas regiões medial (L4), dorsal (L5) e lateral (S1) do pé.

\subsection{3 - Força muscular}

A ação de cada músculo deve ser observada separadamente, anotando-se se a sua força está conservada, diminuída ou abolida. Em casos de pacientes com dor na região lombar, com sintomatologia em membros inferiores, pode-se testar a extensão dos joelhos, a dorsiflexão dos pés e a flexão plantar dos pés ${ }^{(1)}$.

- Extensão do joelho (L2, L3 e L4): Pede-se ao paciente para estender o joelho contra a resistência de sua mão.

- Dorsiflexão do pé e do hálux (L4, L5): Orienta-se o paciente a empurrar o pé para cima, contra a resistência da mão.

- Flexão plantar do pé e hálux (S1): 0 paciente deve forçar o pé para baixo, contra uma resistência.

Nas cervicalgias pode-se testar a flexão $(C 5, C 6)$ e a extensão $(C 6, C 7, C 8)$ no cotovelo, solicitando ao paciente que empurre e puxe o braço contra sua mão ${ }^{(33)}$. Para testar a preensão $(\mathrm{C} 7, \mathrm{C} 8, \mathrm{~T} 1)$ solicite ao paciente que aperte dois dos seus dedos o mais forte possível.

\section{6 - Manobras especiais}

3.6.1 - Sinal de Lasègue: É realizado se o paciente tiver referido lombalgia com irradiação para a perna, sendo um sinal indicativo de compressão radicular. Pode detectar comprometimento de L5 e S1. Consiste na elevação do membro inferior do paciente com o joelho estendido e segurando em torno do calcanhar, acarretando

\section{ANEXO 1 \\ INSTRUMENTO DE AVALIAÇÃO DA COLUNA VERTEBRAL}

\section{I - IDENTIFICAÇÃO}

Nome: Prontuário: Data da avaliação:

Idade: Anos Sexo ( ) Fer Estado ( ) Solteiro ( ) Divorciado Civil: ( ) Casado ( ) Amasiado

Escolaridade: ( ) $1^{\circ} \mathrm{Grau}$ ( ) Viúvo

( ) $2^{\circ} \mathrm{Grau}$

( ) Superior

Local de trabalho: Horário de trabalho:

Ocupação atual:

Ocupações pregressas: estiramento do nervo ciático. 0 paciente deve estar deitado em decúbito dorsal e relaxado. No caso de compressão, ocorre dor no trajeto do nervo ciático. A dorsiflexão do pé, com agravamento da dor, confirma esse sinal ${ }^{(1,12)}$. Deve-se observar o grau de elevação em que a dor ocorre e sua localização. 0 sinal de Lasègue é positivo, quando surge dor abaixo do joelho (panturrilha) e em menos que $60^{\circ}$, sendo que dor, em até $30^{\circ}$, sugere hérnia discal ${ }^{(1,12)}$. 0 aumento da dor, na perna afetada, quando a perna oposta é elevada, confirma a presença de dor radicular e constitui um sinal cruzado positivo ${ }^{(33)}$.

3.6.2- Teste de compressão: Manobra semiológica da região cervical que ajuda a reproduzir as dores irradiadas para os membros superiores, originadas da compressão radicular ${ }^{(4)}$. Consiste na compressão da cabeça com as mãos espalmadas, desencadeando dor na região afetada.

3.6.3 - Teste de Adson: Serve para determinar a permeabilidade da artéria subclávia, que pode estar comprimida por costela cervical ou por contratura dos músculos escalenos. Deve ser realizado nos quadros de cervicobraquialgias acompanhados por alterações vasculares dos membros superiores. Consiste na verificação do pulso do braço que deve ser estendido e rodado externamente, enquanto o paciente roda a cabeça para o lado que está sendo testado. Uma diminuição ou ausência de pulso indica compressão da artéria subclávia ${ }^{(25)}$.

\section{CONSIDERAÇÕES FINAIS}

Neste trabalho, procurou-se apresentar um roteiro básico dos métodos semiológicos que devem ser empregados na exploração postural e na avaliação da coluna vertebral na assistência à saúde em nível primário. Acredita-se que a observância de uma propedêutica, baseada em pesquisas, auxiliará na identificação de problemas e subsidiará a implementação de ações de assistência à saúde, melhorando a sua qualidade.

Peso aproximado:_ $\quad \mathrm{Kg} \quad$ Altura aproximada:__ $\mathrm{m}$

Dominância: ( ) Direita ( ) Esquerda ( ) Ambidestro

II - HISTÓRIA DE SAÚDE

1. ANTECEDENTES PESSOAIS E DE DOENÇAS ASSOCIADAS

( ) Obesidade ( ) Tuberculose ( ) Cirurgia

( ) Câncer ( ) Diabetes mellitus ( ) Outros

Especificar:

( ) Etilismo ( ) Sim ( ) Não ( ) Social Tipo de bebida: Freqüência:

( ) Tabagismo ( ) Sim ( ) Não Cigarros/dia:___ Anos: 2. SINAIS E SINTOMAS GERAIS

( ) Febre ( ) Anorexia ( ) Cefaléia occipital ( ) Depressão ( ) Alterações do equilibrio ( ) Alterações genitourinárias ( ) Alterações intestinais 


( ) Emagrecimento:__ Kg Tempo:__ ( ) Aumento de peso:__ Kg

\section{ASPECTOS POSTURAIS E ERGONÔMICOS}

Colchão: ( ) Adequado Travesseiro: ( ) Baixo ( ) Alto

$$
\text { ( ) Inadequado ( ) Médio ( ) Não usa }
$$

Posição no trabalho: ( ) Sentada ( ) Sem posição fixa ( ) Ortostática ( ) Outra:

Tipo de atividades no trabalho:

Prática de atividade física: ( ) Sim ( ) Não

Tipo:

\section{ASPECTOS PSICOSSOCIAIS E ECONÔMICOS}
( ) Bom
Relacionamento com ( ) Bom

Relacionamento familiar: ( ) Regular colegas de trabalho: ( ) Regular

$$
\text { ( ) Difícil ( ) Difícil }
$$

Relacionamento com ( ) Bom Quer mudar de ( ) Não

chefia(s): ( ) Regular setor de trabalho? ( ) Sim
( ) Difíil
Justifique:

Está envolvido em alguma questão legal trabalhista?

( ) Sim ( ) Não Especifique:

Foi um acidente de trabalho?

( ) Sim ( ) Não Especifique:

III - SINAIS E SINTOMAS ESPECÍFICOS

1. CONSIDERAÇÕES SOBRE AS DORES

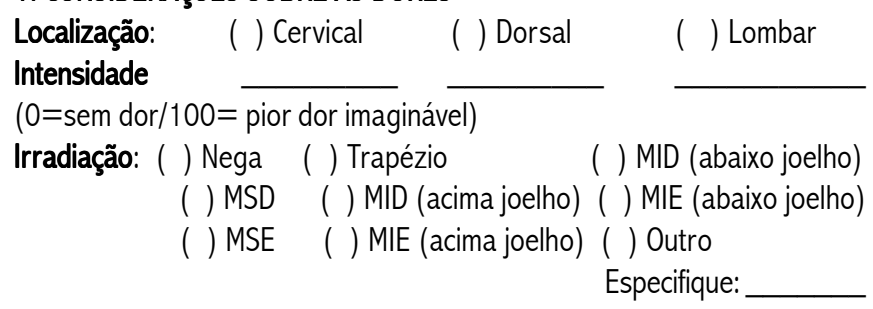

Horário: ( ) Matutina ( ) Vespertina ( ) Noturna ( ) Sem horário fixo Data de início do episódio atual: Início: ( ) Súbita ( ) Gradual

\section{É o primeiro episódio? ( ) Sim ( ) Não}

Especifique o número de episódios anteriores:

Data de início do primeiro episódio:

Estágio: ( ) Aguda (duração de 1-4 semanas) ( ) Subaguda (duração de 5-12 semanas)
( ) Crônica (duração de mais de ( ) Crônica com exarcebação 12 semanas) aguda

$\begin{aligned} & \text { Fatores de ( ) Esforço físico } \\ & \text { piora }\end{aligned}$
$\begin{array}{lll}\text { físico } & \text { Repouso ( ) Posição em pé } \\ \text { ( ) Posição sentada } & \text { ( ) Deambulação ( ) Tensão Emocional } \\ & \text { ( ) Esporte } & \text { ( ) Movimento ( ) Outro }\end{array}$

Fatores que ( ) Repouso ( ) Calor local ( ) Fisioterapia ( ) Medicação aliviam ( ) Movimento ( ) Exercício/alongamento ( ) Outro

Recente história de ( ) Queda

trauma Especifique:

( ) Acidente com veículo

Especifique:

( ) Outro

Especifique:

Fatores associados ( ) Rigidez matinal ( ) Fraqueza muscular

Especifique:
( ) Parestesia
( ) MSD ( ) MID (acima joelho)
( ) MIE (acima joelho)
( ) MSE ( ) MID (abaixo joelho)
( ) MIE (abaixo joelho)
Tratamento ( ) Não ( ) Sim (
( ) Clínico ( ) Fisioterapia
anterior:
( ) Cirúrgia ( ) Outro
Especifique:

\section{IV - EXAME FÍSICO ESPECÍFICO}

\section{INSPEÇÃO ESTÁTICA}

Cabeça: ( ) Normal ( ) Inclinada anteriormente ( ) Inclinada à direita ( ) Inclinada à esquerda

Ombros: ( ) Simétricos ( ) Direito mais elevado

( ) Esquerdo mais elevado

Escápula: ( ) Simétricas ( ) Alada à direita ( ) Plana à direita

( ) Desnivelamento ( ) Alada à esquerda ( ) Plana à esquerda

Quadril: ( ) Normal ( ) Desnivelamento

Membros ( ) Simétricos ( ) Joelhos valgos ( ) Pés planos

inferiores: ( ) Desvio do calcanhar para fora
( ) Hálux
( ) Joelhos varos
( ) Pés cavos
( ) Desvio do calcanhar para dentro

Coluna ( ) Normal ( ) Escoliose ( ) Retificação lordose lombar vertebral: ( ) Hiperlordose cervical ( ) Aumento da cifose dorsal
( ) Hiperlordose lombar
( ) Retificação da lordose cervical

\section{INSPEÇÃO DINÂMICA E PALPAÇÃO}
Marcha
( ) Normal
( ) Antálgica
( ) Patológica
Mobilidade da Coluna Vertebral
Movimentos

\begin{tabular}{ccc} 
Região Cervical & \multicolumn{2}{c}{ Região Dorsolombar } \\
Dor Restriçãa & Dor $\quad$ Restrição
\end{tabular}

Flexão

Extensão

Inclinação à direita

Inclinação à esquerda

Rotação à direita

Rotação à esquerda

Dor à palpação de processos espinhosos:

Alterações do tônus muscular:

\section{AVALIAÇÃO MUSCULAR ESPECÍFICA}

Avaliação da força muscular Músculos

\begin{tabular}{|c|c|}
\hline Glúteo D & ( ) $1($ ) $2($ ) 3() 4() 5 \\
\hline Glúteo E & \\
\hline $\begin{array}{l}\text { Adutores } \\
\text { escapulares }\end{array}$ & ( ) $1($ ) $2($ ) $3($ ) $4($ ) \\
\hline $\begin{array}{l}\text { Eretores } \\
\text { cervicodorsais }\end{array}$ & ${ }_{S}^{()} 1() 2() 3() 4() 5$ \\
\hline $\begin{array}{l}\text { Abdominais } \\
\text { superiores }\end{array}$ & ( ) $1($ ) $2($ ) $3($ ) 4 ( \\
\hline $\begin{array}{l}\text { Abdominais } \\
\text { inferiores }\end{array}$ & ( ) $1($ ) $2($ ) $3($ ) 4 ( \\
\hline $\begin{array}{l}\text { Abdominais } \\
\text { oblíquos }\end{array}$ & ( ) 1 ( ) $2($ ) $3($ ) 4 ( \\
\hline
\end{tabular}

Grau*

*Grau 1 = Esboço de movimento; Grau 2 = Arco de movimento completo sem ação da gravidade; Grau 3 = Arco de movimento completo contra ação da gravidade; Grau 4 = Arco de movimento completo contra resistência parcial; Grau $\mathbf{5}$ = Arco de movimento completo contra resistência total

Encurtamento muscular: Quadríceps ( ) Sim ( ) Não Isquiotibia ( ) Sim ( ) Não Paravertebrais ( ) Sim ( ) Não

\section{EXAMES NEUROLÓGICO}

Caminhar na ponta dos pés $\left(S_{1}\right) \quad$ ） ） Normal ( ) Anormal à direita ( ) Anormal à esquerda

Caminhar nos calcanhares $\left(L_{5}\right) \quad($ ) Normal ( ) Anormal à direita ( ) Anormal à esquerda 
Reflexos

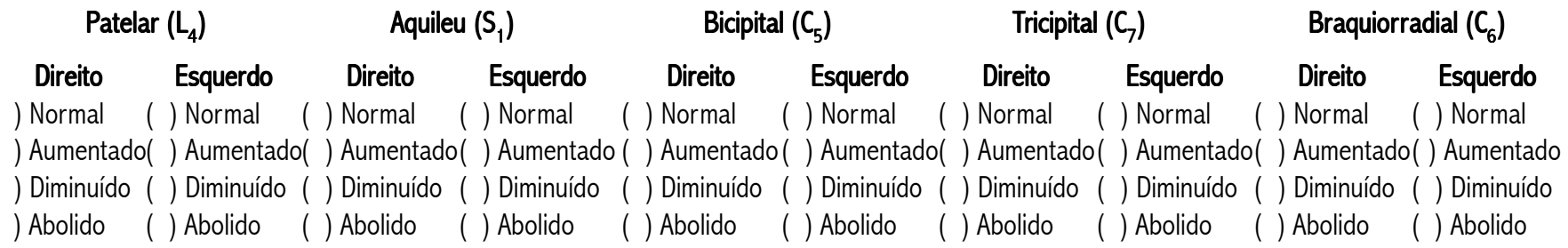

\section{Sensibilidade Tátil}

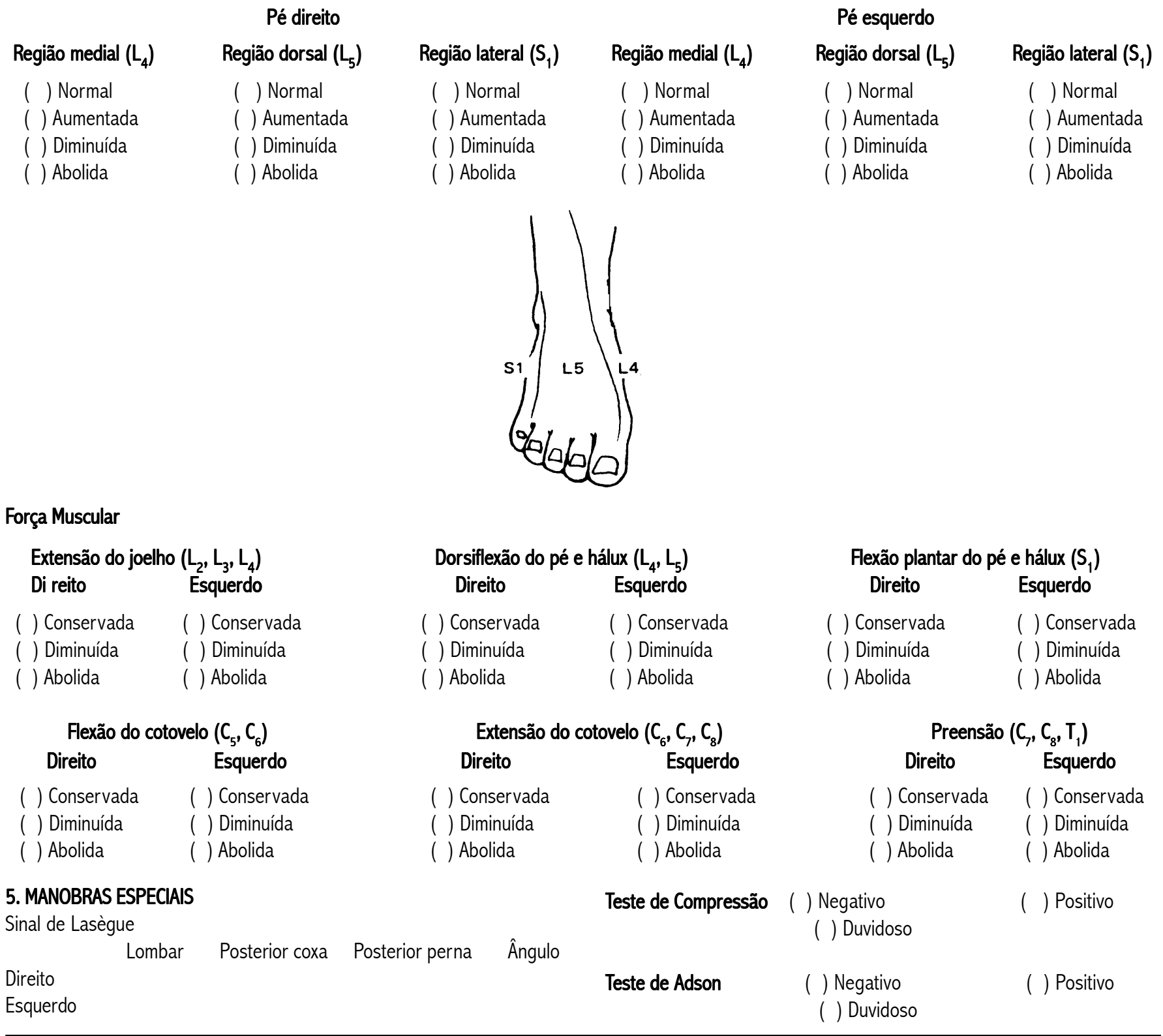

\section{REFERÊNCIAS BIBLIOGRÁFICAS}

1. Bigos S.J. et al. Acute low back pain problems in adults: clinical practice guideline. Rockville: US Department of Health and Human Services; 1994.

2. Guo $\mathrm{H}$ et al. Back pain prevalence in US industry and estimates of lost workdays. Am J Public Health 1999; 89(7): 1029-35.

3. Hagen KB, Thune 0 . Work incapacity from low back pain in the general population. Spine 1998; 23(19): 2091-5.
4. Moreira C, Carvalho MAP. Reumatologia. In: López M, Medeiros JL. Semiologia Médica. $3^{\mathrm{a}}$ ed. Rio de Janeiro: Atheneu; 1990. p. 911 43.

5. Porter RW. Management of back pain. $2^{\text {nd }}$.ed. London: Churchill Livingstone; 1993.

6. Splenger DM. Clinical evaluation of the low back pain region. In: Nordin M, Andersson GBJ, Pope MH. Musculoskeletal disorders in the workplace: principles and practice. St. Louis: Mosby; 1997. p. 277-87. 
7. Weiser S. Psychosocial aspects of occupational musculoskeletal disorders. In: Nordin M, Andersson GBJ, Pope MH. Musculoskeletal disorders in the workplace: principles and practice. St Louis: Mosby; 1997. p. 51-61.

8. Nordin M. et al. Nonspecific low back pain. In: Rom WN. Environmental and occupational medicine. $3^{\mathrm{a}}$ ed. Philadelphia: Linppicott; 1998. p. 947-57.

9. Scott SC, Goldberg MS, Mayo NE, Stock SR, Poitras B. The association between cigarette smoking and back pain in adults. Spine 1999; 24(11): 1090-8.

10. O'Hanlon-Nichols T. Basic assessment series. A review of the adult musculoskeletal system. Am J Nurs 1998; 98(6): 48-52.

11. Bigos SJ, Nordin M, Leger D. Treatment of the acutely injured worker. In: Nordin M, Andersson GBJ, Pope MH. Musculoskeletal disorders in the workplace: principles and practice. St Louis: Mosby; 1997. p.51-61.

12. Borges CA, Ximenes AC. Coluna vertebral. In: Porto CC. Semiologia médica. $3^{\mathrm{a}}$ ed. Rio de Janeiro: Guanabara Koogan; 1997. p. 894905.

13. Jensen MP, Karoly P, Braver S. The measurement of clinical pain intensity: a comparison of six methods. Pain 1986; 27: 117-26.

14. Melzac R. The McGill questionnaire: major properties and scoring methods. Pain 1975; 1: 277-99.

15. Samara AM. Reumatologia. São Paulo: Sarvier; 1985.

16. Cuomo FC et al. Clinical evaluation of the neck and shoulder. In: Nordin M, Andersson GBJ, Pope MH. Musculoskeletal disorders in the workplace: principles and practice. St Louis: Mosby; 1997. p. 359-76.

17. Ramos J Jr. Semiotécnica da observação clínica. $8^{a}$ ed. São Paulo: Sarvier; 1998.

18. Cailliet R. Tecidos moles: dor e incapacidade. São Paulo: Manole; 1979.
19. Messias AR. Dores posturais. Doença postural. In: Seda H. Reumatologia. $2^{\mathrm{a}}$ ed. Rio de Janeiro: Cultura Médica; 1982. p. 140918.

20. Rash PJ. Cinesiologia e anatomia aplicada. $7^{\mathrm{a}}$ ed. Rio de Janeiro: Guanabara Koogan; 1989.

21. Adams RC et al. Jogos, esportes e exercícios para o deficiente físico. $3^{a}$ ed. São Paulo: Manole; 1987.

22. Ortiz J. Semiologia da coluna vertebral. Rev Bras Ortop 1992; 27(3): 93-100.

23. Seda H. Reumatologia. $2^{\mathrm{a}}$ ed. Rio de Janeiro: Cultura Médica; 1982. 1: 182-93.

24. Kapandji IA. Fisiologia articular: esquemas comentados de mecânica humana. São Paulo: Manole; 1980. v. 3.

25. Knoplich J. Enfermidades da coluna vertebral. $2^{\mathrm{a}}$ ed. São Paulo: Panamed Editorial; 1986.

26. Hoppenfeld S. Propedêutica ortopédica: coluna e extremidades. São Paulo: Atheneu; 1998.

27. Jarvis C. Physical examination and health assessment. $2^{\text {nd }}$ ed. Philadelphia: WB Saunders; 1996.

28. Gould JA. Fisioterapia na ortopedia e na medicina do esporte. São Paulo: Manole; 1993.

29. Smith LK, Weiss EL, Lehmkuhl LD. Cinesiologia clínica de Brunnstrom. São Paulo: Manole; 1997.

30. Alter MJ. Science of stretching. Champaign: Human Kinetics; 1988. 31. Contursi TLB et al. Flexibilidade e relaxamento. Rio de Janeiro: Sprint; 1990.

32. Ribeiro SMT, Mello CR, Chahade WH, Dessimoni SPM. Cervicodorsolombalgias. Rev Bras Méd 1986; 43(1/2): 8-16.

33. Bates B, Bickley LS, Hoekelman RA. Propedêutica médica. $6^{a}$ ed. Rio de Janeiro: Guanabara Koogan; 1998. 